yielded about 14 times more calcitonin than normal thyroid tissue. The serum calcium levels rose after total thyroidectomy. In a second case ${ }^{15}$ the patient presented with recurrent thyrotoxicosis after thyroidectomy, and a serum calcium level which never exceeded $4.6 \mathrm{mg} . / 100 \mathrm{ml}$. despite treatment with dihydrotachysterol, calcium, and extract of parathyroid. A second thyroidectomy was performed and the calcium levels rose after operation, thereafter being maintained at normal by small doses of dihydrotachysterol. It has also been noted that in cases of pseudohypoparathyroidism the calcitonin content of the thyroid is greatly in excess of normal, ${ }^{16}{ }^{17}$ but it is not certain whether this is a primary event in the disease or merely represents an accumulation of calcitonin in the thyroid owing to chronic hypocalcaemia, a possibility for which there is experimental support. ${ }^{18}$

The therapeutic possibilities of the hormone would appear to lie in two directions-the treatment of hypercalcaemia and the treatment of excessive bone resorption. G. V. Foster and colleagues, ${ }^{19}$ using purified pig thyrocalcitonin, lowered the plasma levels of calcium in patients with hypercalcaemia associated with bony metastases from breast cancer. The plasma calcium was lowered for 6-18 hours by one injection of the purified preparation. Since in most cases of hypercalcaemia (other than that due to hyperparathyroidism) the raised plasma calcium is not itself the major problem, the therapeutic possibilities in this direction are limited. Thyrocalcitonin might, however, prove useful in averting a parathyroid crisis in cases of severe hyperparathyroidism while preparations for surgery were being made. It may be added in connexion with hyperparathyroidism that, since calcitonin has been shown to have a phosphaturic action and is secreted in response to hypercalcaemia, C. J. Robinson and colleagues $^{8}$ have suggested that tests for hyperparathyroidism depending on phosphate excretion should not be used clinically.

Foster and colleagues ${ }^{10}$ postulate a therapeutic role for calcitonin in cases of osteoporosis. At present the peptide nature of the hormone necessitates its being given by injection, which limits its usefulness, but more potent or longer-acting synthetic analogues might be produced in future which could prove useful in promoting the remineralization of bones depleted of calcium.

1 Hirsch, P. F., Gauthier, G. F., and Munson, P. L., Endocrinology, $1963,73,244$.

- Foster, G.' V., MacIntyre, I., and Pearse, A. G. E., Nature (Lond.), 1964, 203, 1029 .

- Bussolati, G., and Pearse, A. G. E., F. Endocr., 1967, 37, 205.

- Friedman, J., and Raisz, L. G., Science, 1965, 150, 1465.

- Aliapoulios, M. A., Goldhaber, P., and Munson, P. L., ibid., 1966, 151, 330 .

- Wallach, S., Chausmer, A., Mittleman, R., and Dimich, A., Endocrinology, $1967,80,61$.

' Foster, G.' V., Doyle, F. H., Bordier, P., and Matrajt., H., Lancet, 1966, 2, 1428 .

- Robinson, C. J., Martin, T. J., and MacIntyre, I., ibid., 1966, 2,

- Care, A. D., Duncan, T., and Webster, D., F. Endocr., 1967, 37, 155 .

¿Aiiapcalios, M. A., and Munson. P. L., Surg. Forum, 1965, 16, 55.

"Milhaud, G., Moukhtar, M. S., Bourichon, J., and Perault, A. M., C.R. Acad. Sci. (Paris), 1965, 261, 4513.

Williams, G. A., Hargis, G. K., Galloway, W. B., and Henderson, W. J., Proc. Soc. exp. Biol. (N.Y.), 1966, 122, 1273.

is Duncan, T., and Care, A. D., Brit. . . Surg, 1967, 54, 196.

is Chimenes, H... and Klotz, H. P., ibid., 1967, I, 111 .

16 Aliapoulios, M. A., Voekel, E. F., and Munson, P. L., F. clin. Endocr., 1966, 26, 897.

17 Tashiian, A. H., Frantz, A. G., and Lee, J. B., Proc. nat. Acad. Sci. (Wash.), 1966, 56, 1138

18 Gittes, R. F., Munson, P. L., and Toverud, S. U., Fed. Proc., 1966, 25, 496.

10 Foster, G. V., Joplin, G. F., MacIntyre, I., Melvin, K. E. W., and Slack, E., Lancet, 1966, 1, 107.

\section{Problems of Transplantation}

Extensive studies of the pathological changes that occur during the rejection of transplanted organs are still relatively few. One of the outstanding contributors to this field has been Professor K. A. Porter, of St. Mary's Hospital, so it is fitting that he should have edited the proceedings of a symposium held at the College of Pathologists ${ }^{1}$ and now published as a supplement to the fournal of Clinical Pathology. ${ }^{2}$

Professor Porter's own contribution to the volume consists of a beautifully illustrated paper depicting the changes in transplanted kidneys when rejection occurs despite treatment of the recipient with immunosuppressive drugs. He describes four distinct patterns of rejection. First is an acute and immediate reaction within minutes of transplantation. Characteristic microscopical changes are glomerular microthrombi, with red-cell sludging. The lesion is thought to be due to circulating antibodies in pre-sensitized recipients or, when there has been severe blood-group incompatibility, between donor and host. The second form of rejection appears between two and ten days after transplantation. Cellular infiltration and rupture of peritubular capillaries are followed by tubular necrosis. This type of change is similar to that observed in experimental transplants in untreated animals. The third pattern of rejection occurs from 11 days onwards, and the main feature is vasculitis. Immunoglobulins and complement coat the arterioles and glomerular capillaries. Aggregates of platelets are found in the glomerular capillaries and fibrin thrombi in the walls of larger arteries. Organization of platelet thrombi results in narrowing of the interlobular arteries. The fourth type of rejection is insidious and can occur a long time after transplantation. There is subendothelial accumulation of immunoglobulin and complement on the glomerular capillary basement membrane, with progressive slow deterioration of renal function.

The two most promising recent advances in tissue transplantation-namely, the use of heterologous antilymphocyte serum and the application of tissue typing-were discussed by Professor M. F. A. Woodruff and Drs. J. J. Van Rood, A. Van Leeuwen, and J. W. Bruning. Professor Woodruff, who has pioneered the development of antilymphocyte serum, describes a serum prepared in the horse against human lymphocytes which has been used clinically by T. E. Starzl and his colleagues. It would appear from preliminary results that this serum adds to the immunosuppressive action of azathioprine and prednisone without equivalent added toxicity. Lower doses of prednisone can therefore be used, with reduction in its unpleasant and even lethal side-effects when given in high dosage. Dr. Van Rood and his colleagues described two genetically independent leucocyte group systems, one with ten and the other with two antigens. The antigens of the first leucocyte group system have been shown by skin-graft experiments to be transplantation antigens. Preliminary results suggest that matching of lymphocyte groups of donor and recipient improves the chances of successful kidney transplantation.

The remaining papers in this volume provide an excellent background to the present state of knowledge of transplantation immunity, particularly from the pathological point of view. Finally, in an authoritative summing up Professor Woodruff relates the experimental work to present clinical

\footnotetext{
I See Brit. med. F., 1967, 1, 560.
Suppl. F. clin. Path., 1967, 20, ix-xv, 415-554. Published for the College of Pathologists by the British Medical Association. 30s. net.
} 
results and future prospects in the field of transplantation. In addition to the problem of immunological rejection there are other difficulties, notably those in obtaining satisfactory numbers of donors, particularly from cadaver sources. Better methods of storing organs are also needed. Professor Woodruff ends with the hope that transplantation of organs from animals to man may eventually become successful.

The College of Pathologists is to be congratulated on this symposium-the first it has held. The report of it provides an up-to-date account of tissue and organ transplantation which should be of help to all who are interested in this field, and particularly pathologists.

\section{A Disease of Skin and Bowel}

In the last 25 years occasional reports have appeared describing what is apparently a new disease affecting chiefly the skin and the intestines. The condition was first recognized in 1942 by $R$. Degos and his colleagues, ${ }^{12}$ who initially called it "atrophic papulosquamous dermatitis," and later ${ }^{3}$ "malignant atrophic papulosis." An earlier report by W. Köhlmeier ${ }^{4}$ which referred to a case of skin necrosis in a patient thought to have thromboangiitis obliterans clearly describes the same condition, and hence the name KöhlmeierDegos disease has also been used.

The condition is rare. In a recent review W. E. Strole and others ${ }^{5}$ found only 19 reported cases. The majority of these were from European countries, a few from the U.S.A., and one $^{6}$ from Great Britain. Seventeen of the patients were males, and of these 14 were aged under 40 years. The initial presentation is a papular skin lesion on the trunk and limbs. The papules are at first pink or grey, several millimetres in diameter, and appear in crops. They remain unchanged for some tinnc, but later rapidly develop central umbilication and may coalesce to form larger lesions. With time they become less prominent and assume a rather mummified appearance, but they never disappear completely. At this stage the patient feels well, and, apart from the rash and transient burning or pruritus, has no symptoms. After a variable period, which may be weeks or years, abdominal pain, weakness, fatigue, loss of weight, and sometimes diari hoea develop. Intestinal perforation then follows and in most cases it is fatal, because multiple perforations occur either sinultaneously or at intervals. At laparotomy or necropsy the bowel wall is seen to be studded with multiple depressed white patches similar to the skin lesions. In three cases death was due to multiple cerebral infarcts.

Histologically the characteristic lesion is a change in the arterioles and small arteries. The affected vessels are occluded by relatively acellular fibrous thrombi, and the wall of the artery at the site of occlusion shows a subendothelial fibroplasia. The elastic lamina remains intact and at this level there is no inflammatory response either in the vessel wall or in the periarterial tissues. Elsewhere in the artery, however, an arteritis resembling that seen in polyarteritis nodosa may be found. Though clinically the disease presents mainly with skin and intestinal lesions, the arterial changes are in

\footnotetext{
Degos, R., Delort, J., and Tricot, R., Bull. Soc. franç. Derm. Syph., $1942,49,148$.

Lortat-Jacob, E., Garnier, G., and Benoit, C., ibid., 1942, 4), 281.

Kö Brit. F. Derm., 1954, 66, 304.

5 Strole, W. E., Clark, W. H., and Isselbacher, K. J., New Engl. 7. Med.,

6 Hall-Smith, S. P., Proc. roy. Soc. Med., 1964, 57, 519.
}

fact widespread and may be in any organ. The skin lesion is a non-specific combination of epidermal atrophy and dermal sclerosis, and the histological diagnosis rests on finding the characteristic vascular lesion in the small arteries of the reticular dermis.

Laboratory investigations do not reveal any specific changes. The course of the disease appears to be uniformly fatal, and so far all the therapeutic regimens which have been tried have failed.

Is this a new disease? From the published descriptions of the illness the clinical picture is apparently striking and it is unlikely that it would not have been recognized and reported by the astute clinicians of the early years of this century. The condition which it most closely resembles is polyarteritis nodosa. The clinical picture with the emphasis on the skin and the intestines is certainly unlike classical polyarteritis nodosa. Though the main lesion in the small arteries is apparently different from that of polyarteritis, yet some of the published photomicrographs do show a distinct arteritis in parts of the affected vessels. The time course of the illness and the lack of response to adrenal corticosteroids also suggest that though "malignant atrophic papulosis" is primarily a disease of small arteries and arterioles it may be distinct from polyarteritis nodosa. But it seems equally possible that, like Wegener's granulomatosis, it is a variant of a disease with protean manifestations.

\section{A Case for Cannabis?}

The full-page advertisement in The Times ${ }^{1}$ signed by prominent scientists, doctors, and intellectuals, urging that "the law against marihuana is immoral in principle and unworkable in practice," is only one of many recent appeals ${ }^{2}$ in Britain and the U.S.A. for a more permissive attitude.

Marihuana, "pot," and hashish are all forms of cannabis, and are obtained from the flowers or leaves of the female Indian hemp plant, Cannabis sativa. International legal control of cannabis came into being in 1925, when the League of Nations organized its second opium conference. ${ }^{3}$ The Egyptian delegate stated that 30 to $60 \%$ of the patients suffering from insanity in Egypt were cases of chronic hashishism. The conference agreed that the use of Indian hemp and its products should be authorized for medical and scientific purposes only, and that international trade should be strictly controlled. In Britain the Dangerous Drugs Act of 1920 was amended to include cannabis, and it is still included in the 1965 Act.

Cannabis has no known therapeutic value, ${ }^{4}$ and possibly as a result of this there has been little research into its pharmacology in man. Inhaled smoke produces initial effects within a few minutes and maximum response is obtained in half to one hour, persisting for some three to five hours. If the drug is taken in a conducive setting its effects commonly include tranquillity, apathy, and euphoria. Much less frequently fear, aggression, and hilarity are noted, these sometimes being seen when cannabis is used by an extrovert in a stimulating situation. With increasing doses changes in mood are followed by changes in perception including changes in

1 The Times, 24 July 1967.

2 Newsweek, 24 July 1967.

Report of the International Conference on Opium and Dangerous Drugs, Cmnd. 2461, 1925. H.M.S.O.

- Brit. med. F., 1964, 2, 1348.

s Eddy, N. B., Halbach, H., Ishbell, H., and Seevers, M. H., Bull. Wld Hlth Org., 1965, 38, 721 .

- Clba Foundation Study Group 21, Hashish; its Chemistry and Pharmacology, 1965. London. 